\title{
Immunochromatographic assays for ultrasensitive and high specific determination of enrofloxacin in milk, eggs, honey, and chicken meat
}

\author{
Xianlu Lei, ${ }^{1,2}$ Xinxin $X{ }^{1,2}$ Liqiang Liu, ${ }^{1,2 *}$ Hua Kuang, ${ }^{1,2}$ Liguang $X u^{1,2}$ and Chuanlai $X u^{1,2 *}$ (1) \\ ${ }^{1}$ State Key Laboratory of Food Science and Technology, Jiangnan University, Wuxi, 214121, People's Republic of China \\ ${ }^{2}$ International Joint Research Laboratory for Biointerface and Biodetection, and School of Food Science and Technology, Jiangnan University, \\ Wuxi, 214121, People's Republic of China
}

\section{ABSTRACT}

Enrofloxacin, a veterinary antibiotic that persists in food, poses a risk to human health. Here, a monoclonal antibody against enrofloxacin, 1H12, was prepared based on the hapten ENR-1, and showed excellent sensitivity with a $50 \%$ inhibitory concentration $\left(\mathrm{IC}_{50}\right)$ of $0.03 \mathrm{ng} / \mathrm{mL}$. Using this antibody, 2 lateral-flow immunochromatographic assays were developed for determination of enrofloxacin in egg, milk, honey, and chicken meat samples. The detection ranges $\left(\mathrm{IC}_{20}-\mathrm{IC}_{80}\right)$ were $0.16-0.82 \mathrm{ng} / \mathrm{g}, \quad 0.24-1.8 \mathrm{ng} / \mathrm{g}, \quad 0.25-3.6 \mathrm{ng} / \mathrm{g}$, and $0.61-3.9 \mathrm{ng} / \mathrm{g}$ by colloidal gold-immunochromatographic sensor (CG-ICS) analysis, and $0.022-0.42 \mathrm{ng} / \mathrm{g}$, $0.054-0.42 \mathrm{ng} / \mathrm{g}, 0.069-1.4 \mathrm{ng} / \mathrm{g}$, and $0.19-2.2 \mathrm{ng} / \mathrm{g}$ by Eu-fluorescence-immunochromatographic sensor (EFICS) analysis. The intraassay and interassay recovery rates were 88.9 to $108.5 \%$ with coefficients of variation of 1.3 to $7.0 \%$ by CG-ICS analysis, and 88.6 to $113.6 \%$ with coefficients of variation of 1.3 to $8.1 \%$ by EF-ICS analysis. Thus, our newly developed ICS are sensitive and reliable, providing an option for rapid quantitative detection of enrofloxacin in food samples.

Key words: antibody, antibiotic, enrofloxacin, immunochromatographic, strip

\section{INTRODUCTION}

Enrofloxacin (ENR; Figure 1a) is an important member of the fluoroquinolones and possesses excellent antibacterial effects against gram-positive bacteria, gram-negative bacteria, and mycoplasma by inhibiting DNA-gyrase, which is an essential enzyme in prokaryotes (Zhang et al., 2011; Wang et al., 2014). It is widely used for treatment and prophylaxis of diseases, as well as growth promotion in the livestock and aquaculture industries (Chen et al., 2012; Tochi et al., 2016). Although ENR is relatively less toxic compared with

Received February 9, 2021.

Accepted May 24, 2021.

*Corresponding authors: murel@163.com and xcl@jiangnan.edu.cn other antibiotics, drug residues in the bodies of animals caused by unreasonable use may pose a threat to human health via the food chain (Shen et al., 2019a). Some studies have revealed that long-term, low-dose exposure to ENR can induce bacterial resistance, which increases the risk of treatment failures of human diseases (Otero et al., 2016; Li et al., 2019). In addition, allergic reactions and changes in intestinal flora after eating foods containing ENR residues are also issues that cannot be ignored (Wang et al., 2017). Therefore, many countries and organizations have set a maximum residue limit (MRL) owing to the concerns related to ENR residue in animal products (Tochi et al., 2016). Ten years after approving the use of ENR as an antibiotic for poultry, the US Food and Drug Administration (FDA) withdrew this decision in 2005 (Wu et al., 2009). The European Commission has fixed MRL for the sum of ENR plus ciprofloxacin at 100 to $200 \mu \mathrm{g} / \mathrm{kg}$ in chicken tissue, while Japan has fixed the limit at $10 \mu \mathrm{g} / \mathrm{kg}$ in all chicken tissues (Pulgarin et al., 2011; Chen et al., 2012; Wang et al., 2014). The People's Republic of China set MRL at 100 to $300 \mu \mathrm{g} / \mathrm{kg}$ in different animal tissues, and ENR is banned during egg production (Shen et al., 2019a).

The development of analytical technology is an important safeguard to strengthen the regulation of antibiotic residues in biological matrices. Instrumental analysis is currently the most widely used method for monitoring ENR residues due to its high sensitivity and accuracy, with methods including HPLC (Aufartova et al., 2017; Huang et al., 2018), liquid chromatography (LC)-MS (Lolo et al., 2005; Panzenhagen et al., 2016), and surface plasmon resonance (Fernandez et al., 2010). However, these methods not only require expensive equipment, professional skill, and complicated sample pretreatment, but are also low-throughput and time-consuming techniques (Meng and Xi, 2011). Consequently, it is difficult to meet the need for on-site screening of large numbers of samples using these approaches.

In recent years, immunoassays based on specific binding of antigens and antibodies has aroused great inter- 
est in the field of antibiotic residue detection due to the advantages of low cost, portability, high throughput, and time savings, with techniques such as ELISA (Kong et al., 2019), piezoelectric immunosensors (Karaseva and Ermolaeva, 2012), and fluorescence immunoassay (Miao et al., 2016). According to some reports, several immunoassay methods have also been developed for the determination of ENR in animal samples. For example, a highly sensitive and specific ELISA based on a heterologous coating antigen was established by Wang et al. (2014) at a $50 \%$ inhibitory concentration $\left(\mathbf{I C}_{50}\right)$ of $0.07 \mu \mathrm{g} / \mathrm{L}$. Meanwhile, Sheng et al. (2017) reported 2 types of lateral-flow immunochromatographic assays using dyed polymer microspheres and quantum dots for rapid detection of ENR, with visual limits of detection of $1 \mu \mathrm{g} / \mathrm{L}, 5 \mu \mathrm{g} / \mathrm{kg}$, and $10 \mu \mathrm{g} / \mathrm{L}$ in buffer, animal tissue, and milk, respectively. In a study by $\mathrm{Li}$ et al. (2019), either carbon dots or quantum dots were used as donor probes in 2 fluorescence-quenching immunochromatographic assays to monitor ENR with visual limits of detection of 0.5 to $2.5 \mu \mathrm{g} / \mathrm{kg}$ in animal-derived food samples. Other immunoassay methods including indirect competitive-ELISA (ic-ELISA; Huet et al., 2006; Hu et al., 2010, 2019; Kim et al., 2015), colloidal gold immunoassay (Zhao et al., 2008), biomimetic enzyme-linked immunosorbent assay (Wang et al., 2017), fluorescence polarization immunoassay (Shen et al., 2019a), and chemiluminescence enzyme immunoassay (Kim and Kim, 2009; Kim et al., 2013; Yu et al., 2014a,b) have also been reported for the determination of ENR. Although the above-mentioned methods are able to meet the qualitative and semiquantitative analysis requirements for some samples, there is still scope for a rapid quantitative analytical test for ENR, especially for egg samples with more sensitive detection requirements.

In this study, an ultrasensitive and highly specific monoclonal antibody against ENR was prepared using a new hapten. Then, immunoassays based on fluorescence and on gold nanoparticles (GNP) were developed for rapid quantitative determination of ENR in milk, eggs, honey, and chicken samples. The technologies developed help simplify the pre-processing of milk and chicken samples and achieve a lower detection limit for quantitative analysis of egg and honey samples.

\section{MATERIALS AND METHODS}

\section{Materials and Reagents}

The ENR and other quinolone analogs were purchased from Yuanye Bio-Technology Co. Ltd., and 6-aminohexanoic acid was purchased from J\&K Scientific Ltd. Horseradish peroxidase-labeled goat anti-mouse was supplied by Kangcheng Bioengineering. Sigma-Aldrich provided keyhole limpet hemocyanin, BSA, polyethylene glycol, 1-ethyl-3-(3-dimethylaminopropyl) carbodiimide (EDC), $N$-hydroxysuccinimide, Freund's complete adjuvant, and Freund's incomplete adjuvant. Gibco BRL supplied cell culture reagents, including RPMI 1640 cell culture medium, fetal bovine serum, and media supplement. All other reagents were obtained from the National Pharmaceutical Group Chemical Reagent Co. Ltd.

Polyvinylchloride backboard, nitrocellulose (NC) high-flow-plus membranes (Pura-bind RP), CB-SB08 glass fiber membrane, and SX18 absorbance pad were purchased from Whatman-Xinhua Filter Paper Co. Ltd. An HM3035 strip-cutting instrument was supplied by Kinbio Tech Co., Ltd. Membrane strip readers were designed in our laboratory.

\section{Synthesis and Characterization of Hapten and Antigen}

Hapten ENR-1. The ENR-1 (Figure 1b) was synthesized by linking the carboxyl group at position 3 of ENR with the amino group on 6-aminocaproic acid, referring to Wang et al. (2014) and Zhou et al. (2020), with some modifications. In brief, $200 \mathrm{mg}$ of ENR was added to oxalyl chloride $(4 \mathrm{~mL})$ and stirred for $2 \mathrm{~h}$. Then, the solution was dried under nitrogen, the residue was re-dissolved in tetrahydrofuran $(4 \mathrm{~mL})$, and mixed with $250 \mathrm{mg}$ of 6-aminocaproic acid overnight at room

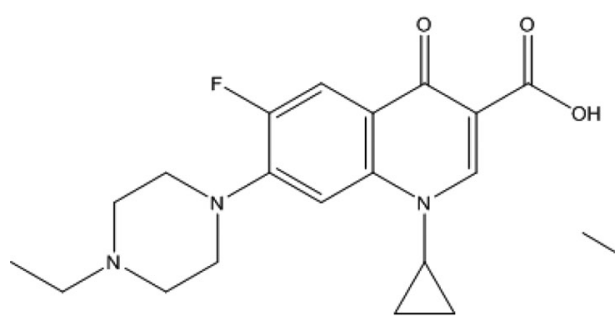

(a)

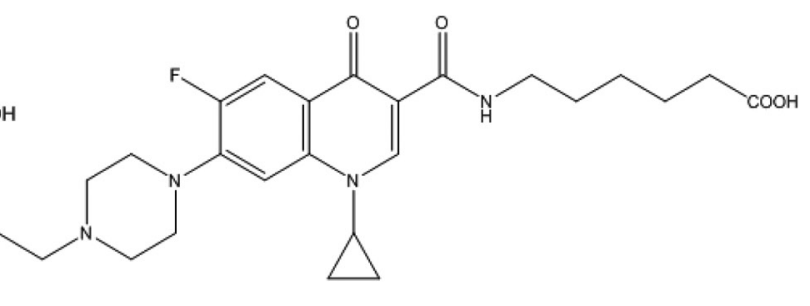

(b)

Figure 1. The structures of enrofloxacin (ENR; a) and hapten ENR-1 (b). 
temperature. After the reaction was terminated with $1 \mathrm{~mL}$ of $\mathrm{H}_{2} \mathrm{O}, 15 \mathrm{~mL}$ of trichloromethane was used to extract the mixture 3 times. All trichloromethane was collected and evaporated under a stream of nitrogen, then the residue was purified by preparative thin layer chromatography on silica gel plates with an elution solvent of methanol/tetrahydrofuran (3/1) containing $3 \%$ acetic acid. Finally, the product, ENR-1, was characterized by LC-MS/MS.

$\boldsymbol{E N R}-1-B S A$. The ENR-1 was connected to carrier BSA using the active ester method, referring to previous studies (Wang et al., 2018, 2020; Lei et al., 2020a). Briefly, $6 \mathrm{mg}$ of ENR-1 and $4.6 \mathrm{mg}$ of $N$-hydroxysuccinimide were dissolved in $\mathrm{N}, \mathrm{N}$-dimethyl formamide (DMF , $500 \mu \mathrm{L}$ ), and then $7.7 \mathrm{mg}$ of EDC was added to the solution after an interval of $10 \mathrm{~min}$. After stirring continuously for $4 \mathrm{~h}$ at room temperature, the activation solution was added dropwise to $15 \mathrm{mg}$ of BSA dissolved in coating buffer solution $(0.05 \mathrm{M}, \mathrm{pH} 9.6,2$ $\mathrm{mL}$ ). The reaction was completed by stirring the mixture overnight at room temperature. The ENR-1-BSA was obtained by dialyzing the solution against PBS (0.01 M, pH 7.4) for $3 \mathrm{~d}$ and it was then stored at $4^{\circ} \mathrm{C}$ for future use. Finally, ENR-1-BSA was characterized by UV-visible spectroscopy.

Ofloxacin-Ovalbumin. The coating antigen ofloxacin (OFL)-ovalbumin (OVA) was obtained by the mixed-anhydride method (Lei et al., 2020b). First, 7.3 $\mathrm{mg}$ of OFL was dissolved in $0.7 \mathrm{~mL}$ of anhydrous DMF and mixed with $5.7 \mu \mathrm{L}$ of tributylamine for $15 \mathrm{~min}$ in an ice bath, and then $3.2 \mu \mathrm{L}$ of isobutyl-chloroformate was added into the solution. After stirring continuously for $1 \mathrm{~h}$ in an ice bath, the mixture was dripped into 15 $\mathrm{mg}$ of OVA dissolved in $2 \mathrm{~mL}$ of coating buffer solution (0.05 M, pH 9.6). The reaction proceeded for $6 \mathrm{~h}$ in an ice bath. The OFL-OVA was obtained by dialyzing the solution against PBS $(0.01 M, \mathrm{pH} 7.4)$ for $3 \mathrm{~d}$ and stored at $4^{\circ} \mathrm{C}$ for future use. The conjugate OFL-OVA was identified by UV-visible spectroscopy.

\section{Preparation and Characterization of the Anti-ENR Monoclonal Antibody}

This animal study was approved by the Institutional Animal Care and Use Committee of Jiangnan University [IACUC Issue Number: JN. No 20201130b2000615(338)], and all procedures strictly abided by the relevant laws and regulations for experimental animal welfare and ethics. Female BALB/c mice (SPF, age $6-8 \mathrm{wk}$, weight 20-24 g) were purchased from Vital River Laboratory Animal Technology Co. Ltd. and kept in a barrier environment at the Experimental Animal Center of Jiangnan University. Two immunogens, including ENR-1-BSA and ENR-BSA, were each used to immu- nize 5 mice by hypodermic injection in the neck and back (Peng et al., 2017; Guo et al., 2018; Lin et al., 2021). Mice were snatched softly and massaged for 2 min before immunization to reduce their tension and pain. The first immunization was executed with $80 \mu \mathrm{g}$ of immunogen emulsified with Freund's complete adjuvant, and then followed by 4 booster immunizations with $40 \mu \mathrm{g}$ of immunogen emulsified with incomplete adjuvant, at intervals of $21 \mathrm{~d}$. From the second booster immunization, serum was collected from the tails of the mice on the seventh day after each immunization and tested by ic-ELISA. High affinity for the coating antigen and ENR standard was the main indicator to evaluate the immune response of the mice, and the mice with the best response were selected to be injected intraperitoneally with $20 \mu \mathrm{g}$ of antigen and killed $3 \mathrm{~d}$ later for cell fusion. The other mice were killed with $\mathrm{CO}_{2}$. For purpose of reducing the experimental interference, immunization and blood collection for all mice were performed at the same time, and serum was tested by another investigator who was unaware of the immunization procedure. The immune response of the mice was evaluated by the following formula: inhibition ratio $=\left[1-\mathrm{OD}_{450}(1 \mathrm{ng} / \mathrm{mL}) / \mathrm{OD}_{450}(0 \mathrm{ng} / \mathrm{mL})\right] \times 100 \%$, where $\mathrm{OD}_{450}$ is the optical density at $450 \mathrm{~nm}$.

Spleen cells prepared from the mice were mixed with Sp2/0 myeloma cells and fused using PEG 4000 purchased from Thermo Fisher Scientific Co. Ltd. (Zhou et al., 2021). A pure cell line that stably secreted anti-ENR antibody was selected through 3 rounds of subcloning, and then injected into the abdominal cavity of mice. One week later, ascites were prepared and purified using the saturated ammonium sulfate method, and the characteristics of the $\mathrm{mAb}$ were tested by ic-ELISA, as previously described (Fan et al., 2012; Li et al., 2018; Shen et al., 2019b).

\section{Preparation of Immunochromatographic Strips}

Colloidal Gold-Labeled mAb and Eu Fluorescence-Labeled $m A \boldsymbol{b}$. Nanogold and fluorescent materials, with excellent optical properties, biocompatibility, and long-term stability, are widely used as probes for immunoassays in various fields (Han et al., 2018; Fang et al., 2020). Colloidal gold nanoparticles (GNP) with a diameter of approximately $15 \mathrm{~nm}$ were synthesized as described in a previous study (Zhang et al., 2015; Lei et al., 2020a; Suryoprabowo et al., 2021), and Eu-fluorescent microspheres (FMP) with a diameter of approximately $210 \mathrm{~nm}$ were purchased from Microdetection Company. The GNP and FMP were bound to the $\mathrm{mAb}$ through electrostatic adsorption (Zeng et al., 2020) and a condensation reaction between the carboxyl and amino groups (Natarajan et 
al., 2019; Suryoprabowo et al., 2021; Zhou et al., 2021), respectively. Briefly, $6 \mathrm{~mL}$ of GNP was transferred into a $15-\mathrm{mL}$ centrifuge tube and the $\mathrm{pH}$ was adjusted to 8.0 with $0.2 \mathrm{M} \mathrm{K}_{2} \mathrm{CO}_{3}$, and then $48 \mu \mathrm{g}$ of $\mathrm{mAb}$ diluted to $0.2 \mathrm{mg} / \mathrm{mL}$ with $0.05 M$ HEPES was added to the solution and mixed. After standing for $45 \mathrm{~min}$ at room temperature, $300 \mu \mathrm{L}$ of $10 \%$ BSA solution was added and allowed to stand for another $2 \mathrm{~h}$ to block the surface of the GNP where no mAb was bound. Finally, the mixture was centrifuged at $7,200 \times g\left(4^{\circ} \mathrm{C}\right)$ for $45 \mathrm{~min}$, then the pellet was re-dissolved in $600 \mu \mathrm{L}$ of resuspension buffer (0.02 M PBS, containing 0.5\% PEG 6000 purchased from Thermo Fisher Scientific Co. Ltd., $5 \%$ sucrose, $0.1 \%$ Tween, and $0.02 \% \mathrm{NaN}_{3}, \mathrm{pH} 7.4$ ) and stored at $4^{\circ} \mathrm{C}$ for further use.

The process of labeling antibodies with FMP was as follows: $100 \mu \mathrm{L}$ of FMP was mixed with $400 \mu \mathrm{L}$ of borate buffer solution (BBS; $0.05 \mathrm{M}, \mathrm{pH} 8.0$ ) in a 2 -mL centrifuge tube. Then, $30 \mu \mathrm{L}$ of EDC $(10 \mathrm{mg} /$ $\mathrm{mL}$ ) was added to the solution and the mixture was shaken continuously at room temperature for $15 \mathrm{~min}$. After centrifuging at $18,900 \times g\left(4^{\circ} \mathrm{C}\right)$ for $10 \mathrm{~min}$, the sediment was re-dissolved in BBS $(0.5 \mathrm{~mL}, 0.05 \mathrm{M}, \mathrm{pH}$ 8.0) and sonicated for $1 \mathrm{~min}$ at $100 \mathrm{~W}$. Next, $70 \mu \mathrm{g}$ of $\mathrm{mAb}$ was added into the solution and shaken for $2 \mathrm{~h}$ at $20^{\circ} \mathrm{C}$, then $55 \mu \mathrm{L}$ of $10 \%$ BSA was added and shaken

(a)

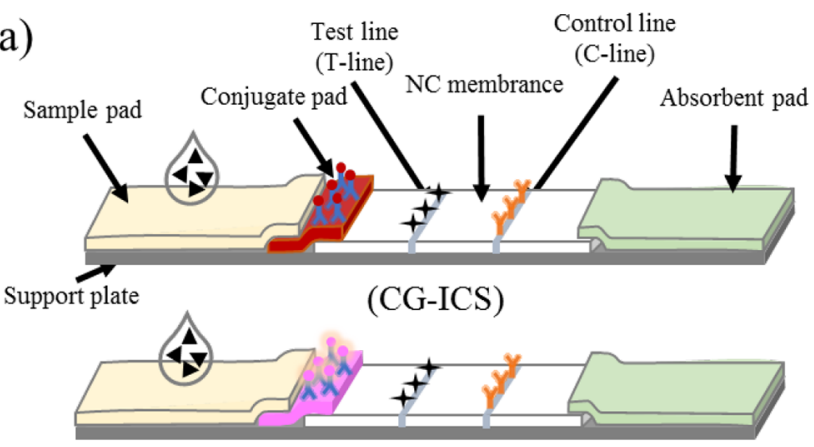

(EF-ICS)

Flow

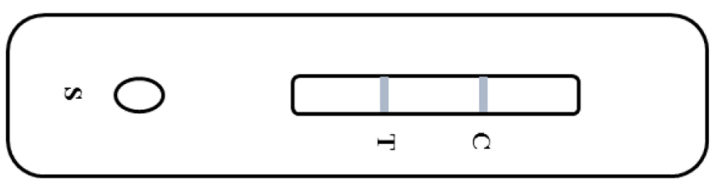

$\Delta$ Coating antigen $\$ Colloidal gold-labeled mAb

+ Target analyte $\quad$ Fluorescence-labeled mAb

入 Anti-ENR mAb Y Goat anti-mouse IgG

for another $2 \mathrm{~h}$ at $20^{\circ} \mathrm{C}$. The solution was then centrifuged at $18,900 \times g\left(4^{\circ} \mathrm{C}\right)$ for $10 \mathrm{~min}$ and washed twice with BBS $(0.5 \mathrm{~mL}, 0.05 \mathrm{M}, \mathrm{pH} 8.0)$. Finally, the pellet was re-dissolved with stock solution (0.05 M BBS, $5 \%$ Tween-20, 2\% BSA) and stored at $4^{\circ} \mathrm{C}$ for further use.

Immunochromatographic Sensor Assembly. The immunochromatographic sensor (ICS) was fabricated as previously reported (Lei et al., 2020a) and consisted of 5 parts (Figure 2a): support plate, absorbent pad, NC membrane, conjugate pad, and sample pad. Before assembly, the coating antigen and goat anti-mouse antibody were separately used to create a control line $(\mathbf{C}$ line) and a test line $(\mathbf{T}$ line) in the central area of the NC membrane with an interval of 5 $\mathrm{mm}$. The conjugate pad was sprayed with colloidal gold (CG)-labeled $\mathrm{mAb}$ or $\mathrm{Eu}$ fluorescence (EF)-labeled $\mathrm{mAb}$, and dried at $37^{\circ} \mathrm{C}$ overnight. The NC membrane was attached to the middle of the support plate, and other components were layered as shown in Figure 2(a). Finally, the board was cut into 4-mm strips and loaded into the card case.

\section{Principle and Performance of the ICS}

The ICS was developed as previously described (Lei et al., 2020a). Briefly, the coated antigen and the

(b)

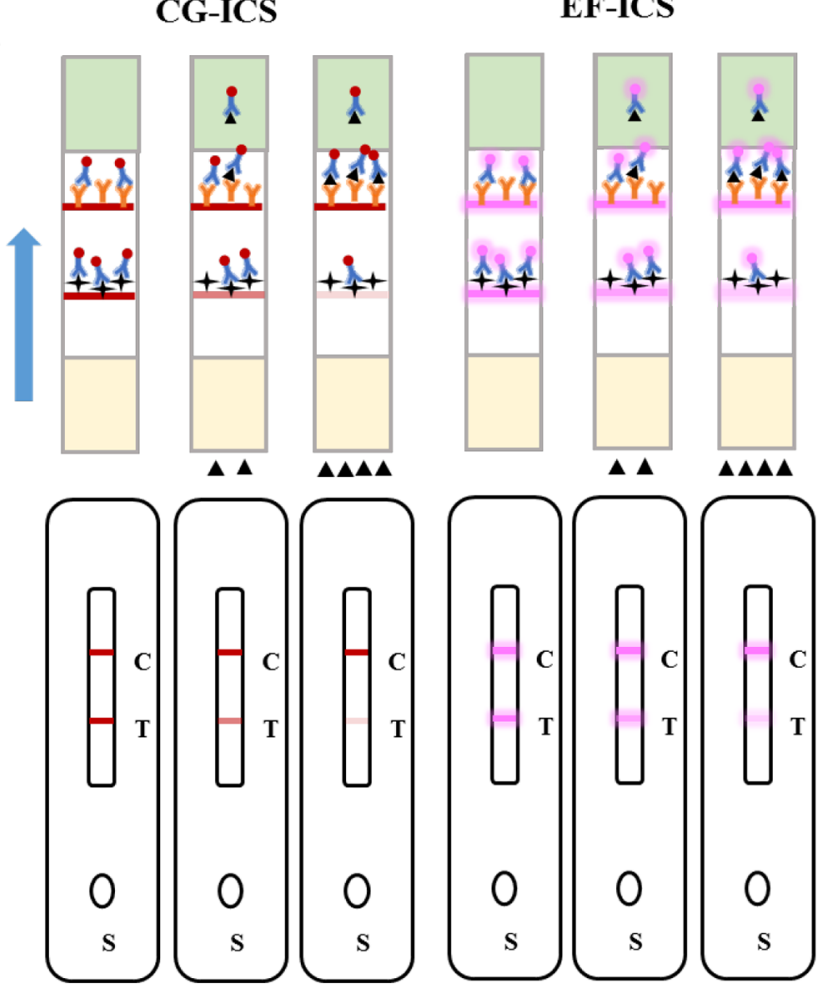

Figure 2. Schematic diagram (a) and illustration (b) of the immunochromatographic sensors [colloidal gold-immunochromatographic sensor (CG-ICS) and Eu-fluorescent-immunochromatographic sensor (EF-ICS)]. ENR = enrofloxacin; NC = nitrocellulose; $\mathrm{S}=$ sample hole. 
target analyte competitively bind to the specific $\mathrm{mAb}$ labeled with GNP or FMP. Figure 2(b) shows roughly the reaction process of the ICS: the sample solution is dropped into the sample hole and flows horizontally toward the absorbent pad under capillary action; the labeled $\mathrm{mAb}$ on the conjugate pad is dissolved in the solution and specifically binds to the antigen. After a complete reaction, any remaining $\mathrm{mAb}$ will be captured by the coated antigen on the $\mathrm{T}$ line to create color, whereas both the antigen-antibody conjugate and the $\mathrm{mAb}$ can bind to the goat anti-mouse antibody on the $\mathrm{C}$ line to confirm the effectiveness of the ICS. The color intensity of both the $\mathrm{T}$ line ( $\mathrm{T}$ value) and the $\mathrm{C}$ line $(\mathrm{C}$ value) are closely related to the amount of labeled $\mathrm{mAb}$ bound and can be measured with a handheld reader. Quantitative analysis of the drug is performed based on the relationship between the antigen concentration and the color intensity of the $\mathrm{T}$ line and the $\mathrm{C}$ line.

The sensitivity of the ICS was tested and evaluated as previously reported (Shen et al., 2019b; Lei et al., 2020a). An ENR standard stock solution was prepared by dissolving $1 \mathrm{mg}$ of ENR in $10 \mathrm{~mL}$ of DMF, and this was then diluted to form a series of gradient standard solutions. When $100 \mu \mathrm{L}$ of standard solution was dripped into the sample hole of the ICS and incubated at $37^{\circ} \mathrm{C}$ for $6 \mathrm{~min}$, the resulting colors of the $\mathrm{T}$ line and $\mathrm{C}$ line could be observed by the naked eye and detected by a handheld reader. For qualitative analysis, the visual colorimetric value (vCMV) was defined as the minimum concentration causing a distinct visible color difference compared with the negative group. The visual cut-off value was defined as the minimum concentration causing a colorless $\mathrm{T}$ line. For quantitative analysis, the $\mathrm{T} / \mathrm{C}$ value was defined as the ratio of color intensity value on the $\mathrm{T}$ line to that on the $\mathrm{C}$ line, and a calibration curve was plotted by fitting the $\mathrm{T} / \mathrm{C}$ value against the concentration of ENR under the logistic mode. The sensitivity of the ICS was evaluated by analyzing the $\mathrm{IC}_{50}$ of the negative sample signal and the quantitative range $\left(\mathrm{IC}_{20}-\mathrm{IC}_{80}\right)$.

\section{Sample Analysis}

Four negative samples of milk, honey, egg, and chicken meat were obtained from the Entry-Exit Inspection and Quarantine Bureau of Jiangsu Province. These were added to ENR standards at different concentrations and used to analyze the actual detection ability of the strips. Based on the consideration of simplified procedures and shortened detection time, the milk and honey samples were directly used for analysis, either undiluted or after being diluted 5 times, respectively, whereas the chicken sample was extracted with a 4 -fold volume of PBS $(1: 4, \mathrm{~g} / \mathrm{mL})$ by rotating for $5 \mathrm{~min}$ fol- lowed by centrifuging at $7,200 \times g\left(4^{\circ} \mathrm{C}\right)$ for $5 \mathrm{~min}$. Egg samples were extracted with acetonitrile for the purpose of reducing matrix interference and improving detection sensitivity. Briefly, the sample was extracted with a 3 -fold volume of acetonitrile $(1: 3, \mathrm{~g} / \mathrm{mL})$ by rotating for $5 \mathrm{~min}$, and then centrifuged for $5 \mathrm{~min}$ at $7,200 \times g\left(4^{\circ} \mathrm{C}\right)$. Then, the upper organic solution was collected and dried under nitrogen flow at $50^{\circ} \mathrm{C}$. The residue was re-dissolved with the same amount of PBS as the sample and used for further analysis.

\section{RESULTS AND DISCUSSION}

\section{Characterization of the Hapten and Antigen}

Hapten $\boldsymbol{E N R}$-1. In this study, the carboxy-terminal arm of ENR (molecular weight 359.4; Figure 1a) was extended by linking to 6 -aminohexanoic acid with the purpose of better exposing the characteristic groups. The result of ENR-1 identified by LC-MS/MS is shown in Figure 3. A selective ion chromatogram of $\mathrm{m} / \mathrm{z}$ 473.25 was generated, and the corresponding product ion spectra at a retention time of $3.71 \mathrm{~min}$ revealed the MS/MS spectrum of target haptens. Therefore, ENR-1 was synthesized successfully.

Antigen ENR-1-BSA and OFL-OVA. Small molecules $(<5,000 \mathrm{Da})$ cannot be used directly for antibody preparation and immunoassay due to their weak immunogenicity. In this study, ENR-1 and OFL were coupled to BSA and OVA to prepare the immunogen and coating antigen, respectively. Figure 4(a) shows the absorption peaks of ENR-1 and BSA at 282 and 279 $\mathrm{nm}$, respectively, whereas ENR-1-BSA appeared as a wider peak than BSA at $279 \mathrm{~nm}$ and showed the same linear trend as ENR-1 from 282 to $500 \mathrm{~nm}$ by the influence of ENR-1 groups bound to the BSA. Figure 4(b) shows that the absorption peaks of OFL appeared at 285 and $332 \mathrm{~nm}$, whereas OVA appeared at $278 \mathrm{~nm}$. The absorption curve of OFL-OVA obviously differed from OVA and appeared to have the characteristic absorption of OFL groups. Therefore, the immunogen ENR-1-BSA and the coating antigen OFL-OVA were prepared successfully.

\section{Characterization of the $m A b$}

High-quality monoclonal antibodies are critical to the development of immunoassay methods, and ic-ELISA was used to select and evaluate antibodies in this study. The immune effects based on different immunogens (ENR-1-BSA and ENR-BSA) and coating antigens (ENR-1-OVA, ENR-OVA, PEF-OVA, and OFL-OVA) were tested. The results (Supplemental Table S1, https: //doi.org/10.6084/m9.figshare.14823606; Lei, 2021) 
revealed that ENR-1-BSA (\#2) and OFL-OVA demonstrated the best $\mathrm{IC}_{50}$ in mouse serum, whereas there were small differences in immune response among mice immunized with same antigens. The monoclonal cell line $1 \mathrm{H} 12$ was prepared by cell fusion and subcloning, and Figure 5(a) shows that the mAb produced by the cell line $1 \mathrm{H} 12$ belonged to the IgG1 subtype. A standard curve was created based on $0.1 \mu \mathrm{g} / \mathrm{mL}$ of OFL-OVA and $0.05 \mu \mathrm{g} / \mathrm{mL}$ of the $\mathrm{mAb}$ (Figure $5 \mathrm{~b}$ ), with the corresponding regression equation $\mathrm{y}=0.0992$ $+1.55 /\left[1+(\mathrm{x} / 0.0303)^{1.22}\right]$. The $\mathrm{IC}_{50}$ and linear range were $0.0303 \mathrm{ng} / \mathrm{mL}$ and $0.00969-0.0945 \mathrm{ng} / \mathrm{mL}\left(\mathrm{IC}_{20}\right.$ to $\left.\mathrm{IC}_{80}\right)$, respectively. The specificity of the $\mathrm{mAb}$ was evaluated by testing 20 quinolones (Supplemental Table S2, https://doi.org/10.6084/m9.figshare.14823606; Lei, 2021), and cross-reactivity (CR) analysis showed that the $\mathrm{mAb}$ was barely able to recognize other quinolones (CR $<0.01 \%)$ except for ofloxacin $(0.13 \%)$, pefloxacin $(0.037 \%)$, and ciprofloxacin $(0.014 \%)$. Therefore, $\mathrm{mAb}$ 1H12 showed high sensitivity and specificity for ENR. Compared with the current best polyclonal antibody prepared by Wang et al. (2014), our mAb $1 \mathrm{H} 12$ not only achieved slightly higher sensitivity but also can be produced permanently.

\section{Sensitivity of the ICS}

The size of colloidal GNP are usually chosen from 10 to $60 \mathrm{~nm}$ in immunoassays. Although large-sized GNP can produce a deep color that helps to improve the sensitivity of the detection method to some degree, they show poor uniform shape and broad size distribution that affect the stability of the detection method (Cui et al., 2015). In this study, the colloidal GNP with a diameter of $15 \mathrm{~nm}$ was synthesized and applied based on the consideration of the excellent stability of the ICS. The GNP and purchased FMP were characterized by high-resolution transmission electron microscopy, and both of them had good uniformity and dispersion as shown in Supplemental Figure S1 (https://doi.org/ 10.6084/m9.figshare.14823606; Lei, 2021).

The CG-ICS was prepared using $0.3 \mathrm{mg} / \mathrm{mL}$ of goat anti-mouse antibody on the $\mathrm{C}$ line and $0.02 \mathrm{mg} / \mathrm{mL}$ of the antigen OFL-OVA on the $\mathrm{T}$ line, whereas the EFICS was prepared using $0.3 \mathrm{mg} / \mathrm{mL}$ of goat anti-mouse antibody and $0.05 \mathrm{mg} / \mathrm{mL}$ of antigen OFL-OVA. The sensitivity of both ICS was tested based on a concentration series of ENR standards (0, 0.078, 0.16, 0.31, $0.63,1.3,2.5$, and $5.0 \mathrm{ng} / \mathrm{mL}$ for CG-ICS, and $0,0.031$,

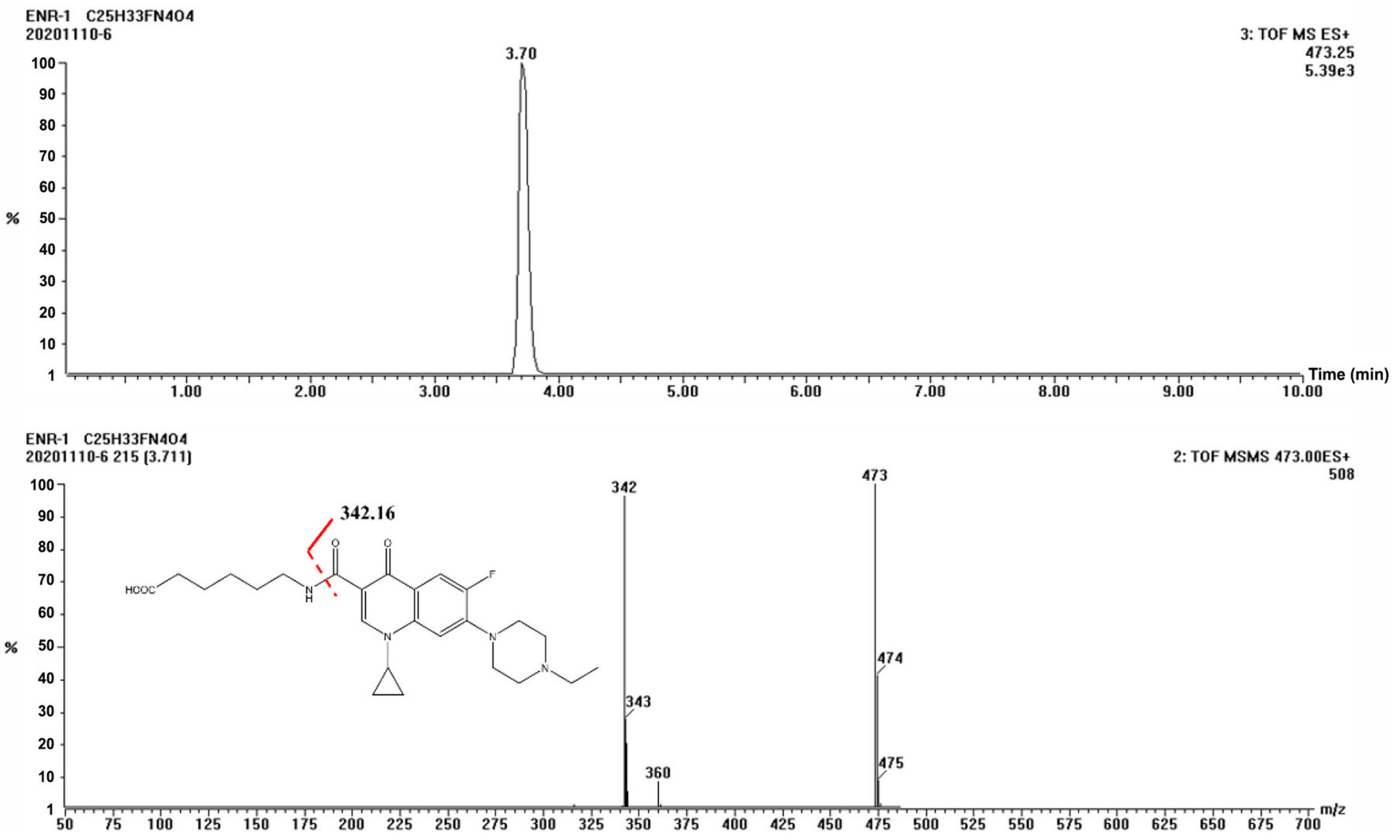

Figure 3. The liquid chromatography (LC)-MS/MS spectrum of enrofloxacin (ENR)-1. 
$0.063,0.13,0.25,0.5,1.0$, and $2.0 \mathrm{ng} / \mathrm{mL}$ for EF-ICS) dissolved into $0.05 \mathrm{M}$ PBS (3\% ON-870). As shown in Figure 6(a) and Figure 7(a), the color intensity on the $\mathrm{T}$ line faded away with the increase in the concentration of the ENR standard solution added into the sample hole, and disappeared completely at $2.5 \mathrm{ng} / \mathrm{mL}$ (CG-ICS) and $1 \mathrm{ng} / \mathrm{mL}$ (EF-ICS). The vCMV value was $0.16 \mathrm{ng} / \mathrm{mL}$ for CG-ICS and $0.063 \mathrm{ng} / \mathrm{mL}$ for EFICS. The color intensity value of the $\mathrm{T}$ line and $\mathrm{C}$ line was read, and the corresponding calibration curves for ENR were constructed by plotting $\mathrm{T} / \mathrm{C}$ (y-axis) against the concentration of ENR (x-axis). The $\mathrm{IC}_{50}$ was 0.17 $\mathrm{ng} / \mathrm{mL}$ by CG-ICS and $0.045 \mathrm{ng} / \mathrm{mL}$ by EF-ICS, and the detection range $\left(\mathrm{IC}_{20}-\mathrm{IC}_{80}\right)$ was $0.057-0.48 \mathrm{ng} / \mathrm{mL}$ and $0.013-0.16 \mathrm{ng} / \mathrm{mL}$, respectively. In previous studies, Kim and Kim (2009) designed an immuno-strip biosensor to detect ENR in a range of 100 to $10,000 \mathrm{ng} /$

\section{(a)}

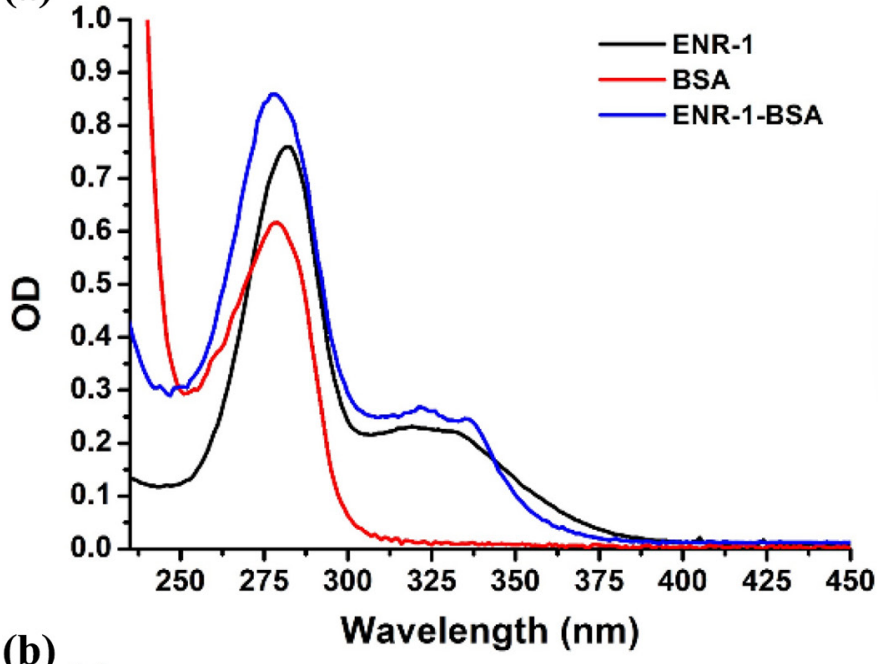

(b)

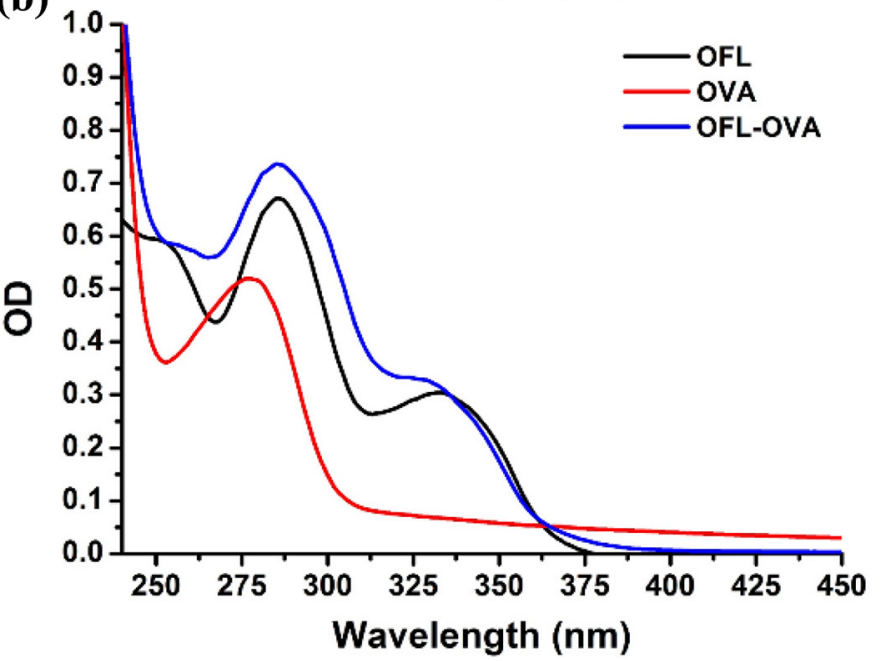

Figure 4. The UV-visible absorption spectra of immunogen ENR1-BSA (a) and coating antigen OFL-OVA (b). OD = optical density; ENR-1 = enrofloxacin hapten; OFL = ofloxacin; OVA = ovalbumin. (a)

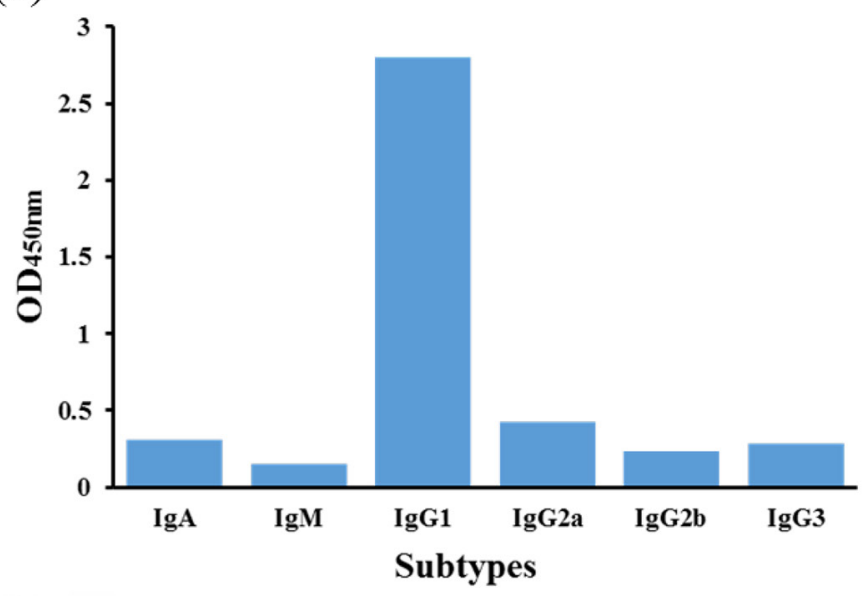

(b)

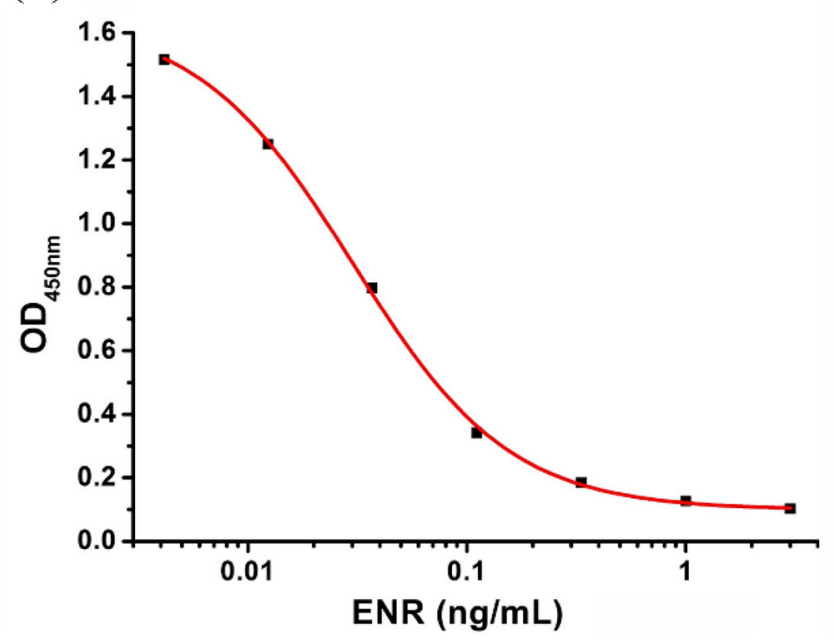

Figure 5. Characterization of the $\mathrm{mAb} 1 \mathrm{H} 12$ by indirect competitive-ELISA: isotype determination (a) and standard inhibition curve (b) for enrofloxacin $(\mathrm{ENR})$. $\mathrm{OD}_{450 \mathrm{~nm}}=$ optical density at $450 \mathrm{~nm}$.

mL. An ENR immunosensor based on electrochemistry was developed by $\mathrm{Wu}$ et al. (2009) with a detection limit of $1 \mathrm{ng} / \mathrm{mL}$. Two fluorescence-quenching immunoassay strips for the detection of ENR were prepared by $\mathrm{Li}$ et al. (2019), with visual cut-off values (limit of detection) of 0.1 and $0.25 \mathrm{ng} / \mathrm{mL}$ in standard solutions. Compared with these immunoassay assays, our 2 ICS, especially for EF-ICS, had a significant improvement in sensitivity. As we all know, high-sensitivity strips are very helpful for simplifying pre-processing when used in real samples.

\section{Determination of ENR in Samples}

Four negative samples (milk, honey, egg, and chicken) were selected to evaluate the detection ability of the strips in actual samples. The samples were spiked with 

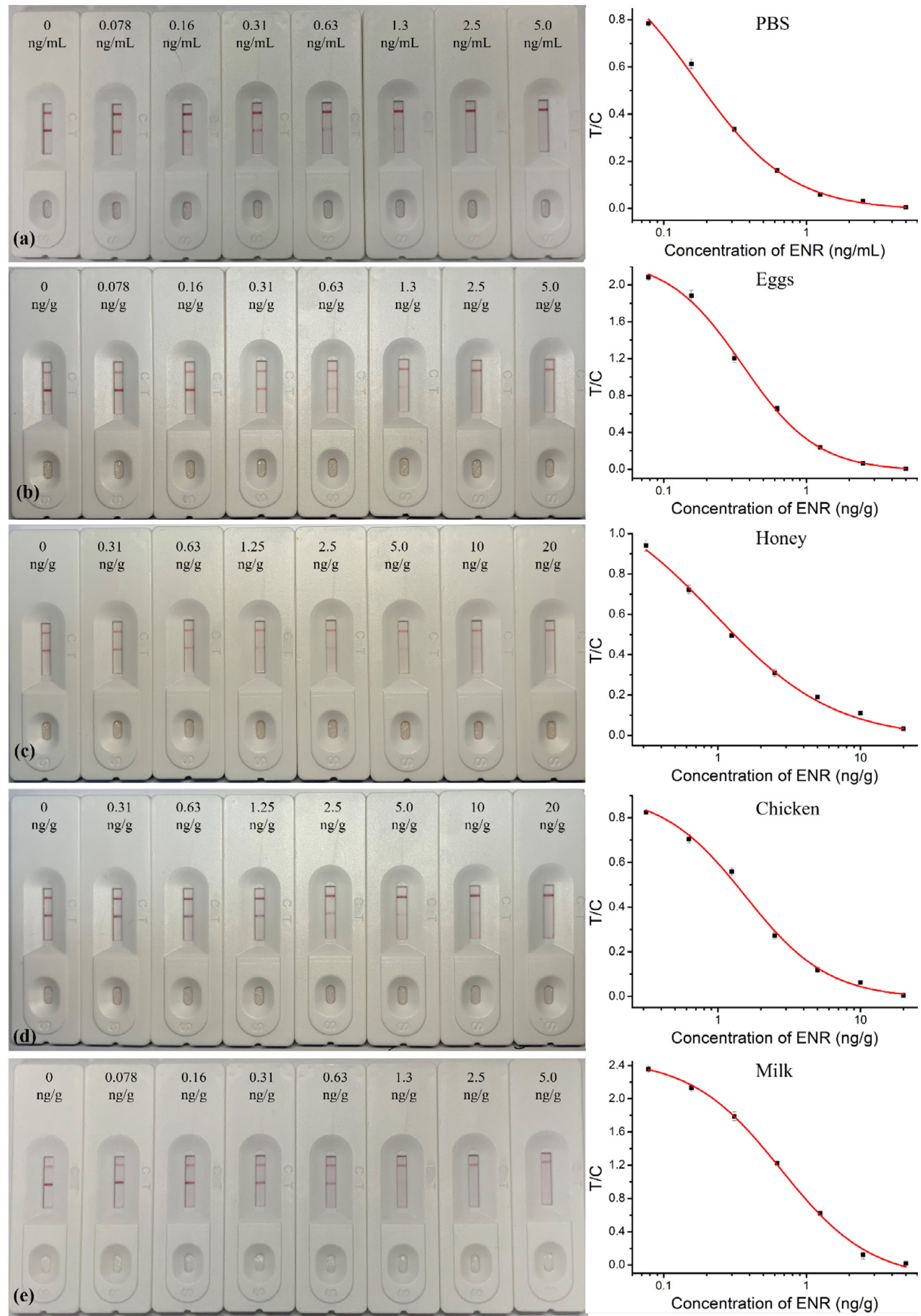

Figure 6. Test pictures of the colloidal gold-immunochromatographic sensor (CG-ICS) and corresponding calibration curves for determination of enrofloxacin (ENR) in PBS (a), eggs (b), honey (c), chicken meat (d), and milk (e). T/C value = the ratio of color intensity value on the test line to that on the control line. Error bars represent the SD of 3 repetitions. 


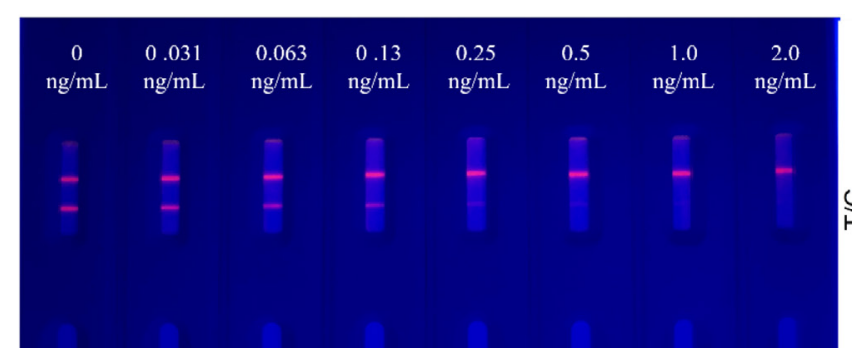

(a)
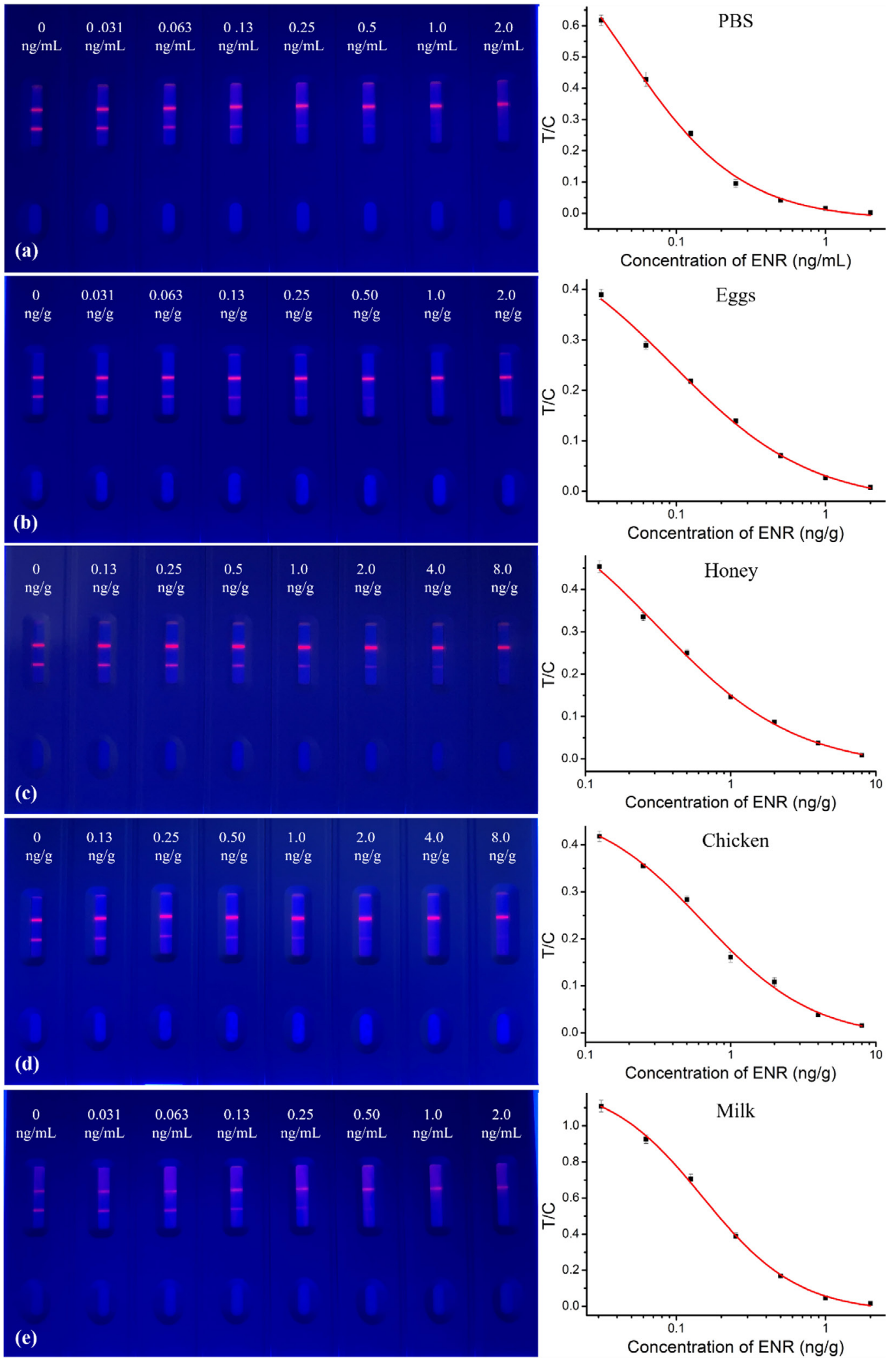

Figure 7. Test pictures of the Eu-fluorescent-immunochromatographic sensor (EF-ICS) and corresponding calibration curves for determination of enrofloxacin (ENR) in PBS (a), eggs (b), honey (c), chicken meat (d), and milk (e). T/C value = the ratio of color intensity value on the test line to that on the control line. The red line near the upper part of the strip window is the control line, and the lower red line is the test line. Error bars represent the SD of 3 repetitions. 


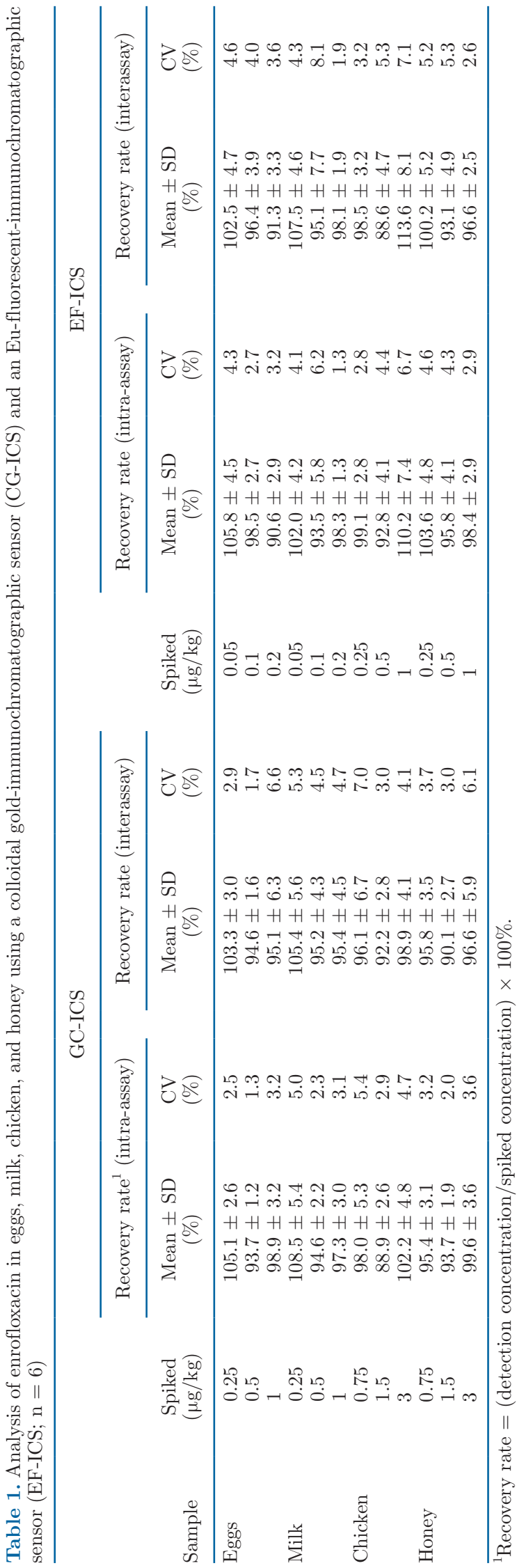

different amounts of ENR standard solution $(0.1 \mathrm{mg} /$ $\mathrm{mL}$ ) before pretreatment. The concentrations of ENR added into egg and milk were 0, 0.078, 0.16, 0.31, 0.63, $1.3,2.5$, and $5.0 \mathrm{ng} / \mathrm{g}$ when used for CG-ICS analysis, and $0,0.031,0.063,0.13,0.25,0.50,1.0$, and $2.0 \mathrm{ng} / \mathrm{g}$ for EF-ICS analysis. The concentrations of ENR added into honey and chicken were $0,0.31,0.63,1.3,2.5,5.0$, 10.0 , and $20.0 \mathrm{ng} / \mathrm{g}$ for CG-ICS analysis, and 0, 0.13, $0.25,0.50,1.0,2.0,4.0$, and $8.0 \mathrm{ng} / \mathrm{g}$ for EF-ICS analysis. Three replicates were created for each sample.

The test pictures of the strips and corresponding calibration curves for CG-ICS and EF-ICS are shown in Figure 6 and Figure 7, respectively, and the performance of the strips in milk, honey, egg and chicken samples was as follows. For qualitative analysis, the results showed that the vCMV from CG-ICS analysis was $0.31 \mathrm{ng} / \mathrm{g}$ for egg, milk, and honey samples, and 1.3 $\mathrm{ng} / \mathrm{g}$ for chicken. The vCMV from EF-ICS analysis was $0.13 \mathrm{ng} / \mathrm{g}$ for egg, milk, and chicken samples, and 0.50 $\mathrm{ng} / \mathrm{mL}$ for honey. The visual cut-off values in egg, milk, honey, and chicken were $2.5,2.5,10$, and $20 \mathrm{ng} / \mathrm{g}$, respectively, for CG-ICS analysis, and 0.50, 1.0, 8.0, and $4.0 \mathrm{ng} / \mathrm{g}$, respectively, for EF-ICS analysis. All these results indicate that the 2 developed methods can make a good qualitative judgment on samples when read by the naked eye. For quantitative analysis, the results of CGICS analysis of egg, milk, honey, and chicken samples produced $\mathrm{IC}_{50}$ values of $0.36,0.66,0.95$, and $1.6 \mathrm{ng} / \mathrm{g}$, respectively, and the detection ranges were $0.16-0.82$, $0.24-1.8,0.25-3.6$, and $0.61-3.9 \mathrm{ng} / \mathrm{g}$. The result of EFICS analysis of egg, milk, honey, and chicken samples produced $\mathrm{IC}_{50}$ values of $0.095,0.15,0.31$, and $0.65 \mathrm{ng} / \mathrm{g}$, respectively, and the detection ranges were $0.022-0.42$, $0.054-0.42,0.069-1.4$, and $0.19-2.2 \mathrm{ng} / \mathrm{g}$.

The sensitivity of our ICS was affected by complex sample matrices that interfere with the combination of analytes and antibodies. Egg extracted with acetonitrile have the least effect on sensitivity of ICS according to $\mathrm{IC}_{50}$ values, followed by milk, honey, and chicken samples with sample pretreatments. Two fluorescencequenching immunoassay strips prepared by $\mathrm{Li}$ et al. (2019) show the cut-off values (limit of detection) were 0.5 to $2.5 \mathrm{ng} / \mathrm{mL}$ in animal-derived food samples (crucian, perch, pork, beef, chicken, and milk). Zhao et al. (2008) developed a lateral-flow colloidal gold immunoassay strip for the detection of ENR with the $\mathrm{IC}_{50}$ of $0.935 \mathrm{ng} / \mathrm{mL}$ in the standard samples. Compared with the above studies and other immunoassay methods, our 2 methods demonstrated excellent detection sensitivity, which will be able to meet the needs of market detection.

The recovery test was performed on 4 samples spiked with 3 different concentrations of ENR, and the results are shown in Table 1. Six replicates were analyzed for 
each sample. The recovery rate in 4 samples using CGICS was 88.9 to $108.5 \%$ with coefficients of variation $(\mathbf{C V})$ of 1.3 to $5.4 \%$ for intraassay variation, and 90.1 to $105.4 \%$ with CV of 1.7 to $7.0 \%$ for interassay variation. Meanwhile, the recovery rates using EF-ICS were 90.6 to $110.2 \%$ with CV of 1.3 to $6.7 \%$ for intraassay, and 88.6 to $113.6 \%$ with CV of 1.9 to $8.1 \%$ for interassay. Therefore, the developed CG-ICS and EF-ICS were reliable and sensitive for the determination of ENR in real samples.

\section{CONCLUSIONS}

In this study, we prepared a highly specific and sensitive mAb, 1H12, against ENR based on the hapten ENR-1, and OFL-OVA was selected as the perfect coating antigen with an $\mathrm{IC}_{50}$ of $0.03 \mathrm{ng} / \mathrm{mL}$ in ic-ELISA. Then, 2 lateral-flow immunochromatographic strips, CG-ICS and EF-ICS, were developed for the determination of ENR in milk, honey, egg, and chicken meat samples. Calibration curves were plotted by fitting the $\mathrm{T} / \mathrm{C}$ values against the concentration of ENR, and the results showed that both ICS achieved low detection limits with simple sample pretreatment. Furthermore, good stability and reliability were demonstrated by testing the recovery rate of ENR from ENR-spiked samples. All in all, the developed CG-ICS and EF-ICS exhibited the advantages of simplicity, time savings, sensitivity, and reliability, and they have potential for the rapid on-site screening of ENR in large-scale samples.

\section{ACKNOWLEDGMENTS}

This work was financially supported by the National Key R\&D Program (2019YFC1604803, China). The authors have not stated any conflicts of interest.

\section{REFERENCES}

Aufartova, J., I. Brabcova, M. E. Torres-Padron, P. Solich, Z. Sosa-Ferrera, and J. J. Santana-Rodriguez. 2017. Determination of fluoroquinolones in fishes using microwave-assisted extraction combined with ultra-high performance liquid chromatography and fluorescence detection. J. Food Compos. Anal. 56:140-146. https:/ /doi.org/10.1016/j.jfca.2016.12.012.

Chen, X., H. Xu, W. Lai, Y. Chen, X. Yang, and Y. Xiong. 2012. A sensitive chromatographic strip test for the rapid detection of enrofloxacin in chicken muscle. Food Addit. Contam. Part A Chem. Anal. Control Expo. Risk Assess. 29:383-391. https://doi.org/10 $.1080 / 19440049.2011 .641509$.

Cui, X., Y. Huang, J. Wang, L. Zhang, Y. Rong, W. Lai, and T. Chen. 2015. A remarkable sensitivity enhancement in a gold nanoparticle-based lateral flow immunoassay for the detection of Escherichia coli O157:H7. RSC Advances 5:45092-45097. https://doi.org/10 .1039/C5RA06237C.

Fan, G. Y., R. S. Yang, J. Q. Jiang, X. Y. Chang, J. J. Chen, Y. H. Qi, S. X. Wu, and X. F. Yang. 2012. Development of a classspecific polyclonal antibody-based indirect competitive ELISA for detecting fluoroquinolone residues in milk. J. Zhejiang Univ. Sci. B 13:545-554. https://doi.org/10.1631/jzus.B1200001.

Fang, B., S. Xu, Y. Huang, F. Su, Z. Huang, H. Fang, J. Peng, Y. Xiong, and W. Lai. 2020. Gold nanorods etching-based plasmonic immunoassay for qualitative and quantitative detection of aflatoxin M1 in milk. Food Chem. 329:127160. https://doi.org/10.1016/j .foodchem.2020.127160.

Fernandez, F., K. Hegnerova, M. Piliarik, F. Sanchez-Baeza, J. Homola, and M. P. Marco. 2010. A label-free and portable multichannel surface plasmon resonance immunosensor for on site analysis of antibiotics in milk samples. Biosens. Bioelectron. 26:1231-1238. https://doi.org/10.1016/j.bios.2010.06.012.

Guo, L., X. Wu, L. Liu, H. Kuang, and C. Xu. 2018. Gold nanoparticle-based paper sensor for simultaneous detection of 11 benzimidazoles by one monoclonal antibody. Small 14:1701782. https://doi .org/10.1002/smll.201701782.

Han, J., L. Zhang, L. Hu, K. Xing, X. Lu, Y. Huang, J. Zhang, W. Lai, and T. Chen. 2018. Nanozyme-based lateral flow assay for the sensitive detection of Escherichia coli O157:H7 in milk. J. Dairy Sci. 101:5770-5779. https://doi.org/10.3168/jds.2018-14429.

Hu, K., X. Y. Huang, Y. S. Jiang, W. Fang, and X. L. Yang. 2010. Monoclonal antibody based enzyme-linked immunosorbent assay for the specific detection of ciprofloxacin and enrofloxacin residues in fishery products. Aquaculture 310:8-12. https://doi.org/ 10.1016/j.aquaculture.2010.08.008.

Hu, S., B. L. Fang, Z. Huang, Y. Chen, D. F. Liu, K. Y. Xing, J. Peng, and W. H. Lai. 2019. Using molecular descriptors for assisted screening of heterologous competitive antigens to improve the sensitivity of ELISA for detection of enrofloxacin in raw milk. J. Dairy Sci. 102:6037-6046. https://doi.org/10.3168/jds.2018-16048.

Huang, W., P. Wang, P. Jiang, X. Dong, and S. Lin. 2018. Preparation and application of a restricted access material with hybrid poly(glycerol mono-methacrylate) and cross-linked bovine serum albumin as hydrophilic out layers for directly on-line high performance liquid chromatography analysis of enrofloxacin and gatifloxacin in milk samples. J. Chromatogr. A 1573:59-65. https:// doi.org/10.1016/j.chroma.2018.08.067.

Huet, A. C., C. Charlier, S. A. Tittlemier, G. Singh, S. Benrejeb, and P. Delahaut. 2006. Simultaneous determination of (fluoro)quinolone antibiotics in kidney, marine products, eggs, and muscle by enzyme-linked immunosorbent assay (ELISA). J. Agric. Food Chem. 54:2822-2827. https://doi.org/10.1021/jf052445i.

Karaseva, N. A., and T. N. Ermolaeva. 2012. A piezoelectric immunosensor for chloramphenicol detection in food. Talanta 93:44-48. https://doi.org/10.1016/j.talanta.2011.12.047.

Kim, N. G., M. A. Kim, Y. I. Park, T. S. Jung, S. W. Son, B. So, and H. G. Kang. 2015. Magnetic nanoparticle based purification and enzyme-linked immunosorbent assay using monoclonal antibody against enrofloxacin. J. Vet. Sci. 16:431-437. https://doi.org/10 $.4142 /$ jvs.2015.16.4.431.

Kim, S., J. Ko, and H. B. Lim. 2013. Application of magnetic and core-shell nanoparticles to determine enrofloxacin and its metabolite using laser induced fluorescence microscope. Anal. Chim. Acta 771:37-41. https://doi.org/10.1016/j.aca.2013.02.009.

Kim, Y. K., and H. Kim. 2009. Immuno-strip biosensor system to detect enrofloxacin residues. J. Ind. Eng. Chem. 15:229-232. https:/ /doi.org/10.1016/j.jiec.2008.10.007.

Kong, D., X. Wu, Y. Li, L. Liu, S. Song, Q. Zheng, H. Kuang, and C. Xu. 2019. Ultrasensitive and eco-friendly immunoassays based monoclonal antibody for detection of deoxynivalenol in cereal and feed samples. Food Chem. 270:130-137. https://doi.org/10.1016/j foodchem.2018.07.075.

Lei, X. 2021. Supplementary material for "Immunochromatographic assays for ultrasensitive and high specific determination of enrofloxacin in milk, eggs, honey, and chicken".docx. figshare. Figure. https://doi.org/https://doi.org/10.6084/m9.figshare.14823606.v1.

Lei, X., X. Xu, L. Liu, H. Kuang, L. Xu, C. Hao, and C. Xu. 2020a. Rapid quantitative determination of fentanyl in human urine and serum using a gold-based immunochromatographic strip sensor. J. Mater. Chem. B Mater. Biol. Med. 8:8573-8584. https://doi.org/ 10.1039/D0TB01509A. 
Lei, X. L., X. X. Xu, L. Q. Liu, H. Kuang, L. G. Xu, and C. L. Hao. 2020b. Immunochromatographic test strip for the rapid detection of tricaine in fish samples. Food Agric. Immunol. 31:687-699. https://doi.org/10.1080/09540105.2020.1752155.

Li, J. J., A. M. Zhi, G. C. Jia, H. Nie, and L. Z. Ai. 2018. Development of an ic-ELISA and immunochromatographic strip for detection of sparfloxacin in honey. Food Agric. Immunol. 29:147-158. https:// doi.org/10.1080/09540105.2017.1364706.

Li, S. J., Y. N. Wang, X. Q. Mu, W. Sheng, J. P. Wang, and S. Wang. 2019. Two fluorescence quenching immunochromatographic assays based on carbon dots and quantum dots as donor probes for the determination of enrofloxacin. Anal. Methods-UK 11:2378-2384. https://doi.org/10.1039/C9AY00154A.

Lin, L., L. Xu, H. Kuang, J. Xiao, and C. Xu. 2021. Ultrasensitive and simultaneous detection of 6 nonsteroidal anti-inflammatory drugs by colloidal gold strip sensor. J. Dairy Sci. 104:2529-2538. https:/ /doi.org/10.3168/jds.2020-19500.

Lolo, M., S. Pedreira, C. Fente, B. I. Vazquez, C. M. Franco, and A. Cepeda. 2005. Study of enrofloxacin depletion in the eggs of laying hens using diphasic dialysis extraction/purification and determinative HPLC-MS analysis. J. Agric. Food Chem. 53:2849-2852. https://doi.org/10.1021/jf048015u.

Meng, M., and R. M. Xi. 2011. Review: Current development of immunoassay for analyzing veterinary drug residue in foods and food products. Anal. Lett. 44:2543-2558. https://doi.org/10.1080/ 00032719.2011 .551863

Miao, Y.-B., N. Gan, H.-X. Ren, T. Li, Y. Cao, F. Hu, and Y. Chen. 2016. Switch-on fluorescence scheme for antibiotics based on a magnetic composite probe with aptamer and hemin/G-quadruplex coimmobilized nano-Pt-luminol as signal tracer. Talanta 147:296301. https://doi.org/10.1016/j.talanta.2015.10.005.

Natarajan, S., F. Su, J. Jayaraj, M. I. I. Shah, and Y. Huang. 2019. A paper microfluidics-based fluorescent lateral flow immunoassay for point-of-care diagnostics of non-communicable diseases. Analyst 144:6291-6303. https://doi.org/10.1039/C9AN01382B.

Otero, J. A., D. Garcia-Mateos, A. de la Fuente, J. G. Prieto, A. I. Alvarez, and G. Merino. 2016. Effect of bovine ABCG2 Y581S polymorphism on concentrations in milk of enrofloxacin and its active metabolite ciprofloxacin. J. Dairy Sci. 99:5731-5738. https: //doi.org/10.3168/jds.2015-10593.

Panzenhagen, P. H., W. S. Aguiar, R. Gouvea, A. M. de Oliveira, F. Barreto, V. L. Pereira, and M. H. Aquino. 2016. Investigation of enrofloxacin residues in broiler tissues using ELISA and LC-MS/ MS. Food Addit. Contam. Part A Chem. Anal. Control Expo. Risk Assess. 33:639-643. https://doi.org/10.1080/19440049.2016 .1143566

Peng, J., L. Liu, H. Kuang, G. Cui, and C. Xu. 2017. Development of an icELISA and immunochromatographic strip for detection of norfloxacin and its analogs in milk. Food Agric. Immunol. 28:288 298. https://doi.org/10.1080/09540105.2016.1263987.

Pulgarin, J. A. M., A. A. Molina, and S. R. Munoz. 2011. Rapid chemiluminescent determination of enrofloxacin in eggs and veterinary drugs. Anal. Lett. 44:2194-2208. https://doi.org/10.1080/ 00032719.2010 .546029$.

Shen, X., J. Chen, S. Lv, X. Sun, B. B. Dzantiev, S. A. Eremin, A. V. Zherdev, J. Xu, Y. Sun, and H. Lei. 2019a. Fluorescence polarization immunoassay for determination of enrofloxacin in pork liver and chicken. Molecules 24:4462. https://doi.org/10.3390/ molecules24244462.

Shen, X. Y., X. L. Wu, L. Q. Liu, and H. Kuang. 2019b. Development of a colloidal gold immunoassay for the detection of four eugenol compounds in water. Food Agric. Immunol. 30:1318-1331. https:/ /doi.org/10.1080/09540105.2019.1687658.

Sheng, W., S. J. Li, Y. Liu, J. P. Wang, Y. Zhang, and S. Wang. 2017. Visual and rapid lateral flow immunochromatographic assay for enrofloxacin using dyed polymer microspheres and quantum dots. Microchimica Acta 184:4313-4321. https://doi.org/10.1007/ s00604-017-2474-y.

Suryoprabowo, S., L. Liu, H. Kuang, G. Cui, and C. Xu. 2021. Fluorescence based immunochromatographic sensor for rapid and sensitive detection of tadalafil and comparison with a gold lateral flow immunoassay. Food Chem. 342:128255. https://doi.org/10.1016/j .foodchem.2020.128255.

Tochi, B. N., G. Khaemba, J. Isanga, D. Mukunzi, L. Q. Liu, J. Peng, H. Kuang, and C. L. Xu. 2016. Monoclonal antibody for the development of specific immunoassays to detect Enrofloxacin in foods of animal origin. Food Agric. Immunol. 27:435-448. https://doi.org/ 10.1080/09540105.2015.1089844.

Wang, J., Y. X. Sang, W. H. Liu, N. Liang, and X. H. Wang. 2017. The development of a biomimetic enzyme-linked immunosorbent assay based on the molecular imprinting technique for the detection of enrofloxacin in animal-based food. Anal. Methods-UK 9:6682-6688. https://doi.org/10.1039/C7AY02321A.

Wang, Z., L. Guo, L. Liu, H. Kuang, and C. Xu. 2018. Colloidal goldbased immunochromatographic strip assay for the rapid detection of three natural estrogens in milk. Food Chem. 259:122-129. https: //doi.org/10.1016/j.foodchem.2018.03.087.

Wang, Z., X. Wu, L. Liu, L. Xu, H. Kuang, and C. Xu. 2020. Rapid and sensitive detection of diclazuril in chicken samples using a gold nanoparticle-based lateral-flow strip. Food Chem. 312:126116. https://doi.org/10.1016/j.foodchem.2019.126116.

Wang, Z., H. Zhang, H. Ni, S. Zhang, and J. Shen. 2014. Development of a highly sensitive and specific immunoassay for enrofloxacin based on heterologous coating haptens. Anal. Chim. Acta 820:152158. https://doi.org/10.1016/j.aca.2014.02.043.

Wu, C. C., C. H. Lin, and W. S. Wang. 2009. Development of an enrofloxacin immunosensor based on label-free electrochemical impedance spectroscopy. Talanta 79:62-67. https://doi.org/10.1016/ j.talanta.2009.03.006

Yu, F., S. Yu, L. Yu, Y. Li, Y. Wu, H. Zhang, L. Qu, and B. Harrington. 2014a. Determination of residual enrofloxacin in food samples by a sensitive method of chemiluminescence enzyme immunoassay. Food Chem. 149:71-75. https://doi.org/10.1016/j .foodchem.2013.10.024

Yu, S., F. Yu, H. Zhang, L. Qu, and Y. Wu. 2014b. Optimization of condition for conjugation of enrofloxacin to enzymes in chemiluminescence enzyme immunoassay. Spectrochim. Acta A Mol. Biomol. Spectrosc. 127:47-51. https://doi.org/10.1016/j.saa.2014.02.019.

Zeng, L., X. Wu, L. Liu, L. Xu, H. Kuang, and C. Xu. 2020. Production of a monoclonal antibody for the detection of vitamin B1 and its use in an indirect enzyme-linked immunosorbent assay and immunochromatographic strip. J. Mater. Chem. B Mater. Biol. Med. 8:1935-1943. https://doi.org/10.1039/C9TB02839K.

Zhang, H. T., J. Q. Jiang, Z. L. Wang, X. Y. Chang, X. Y. Liu, S. H. Wang, K. Zhao, and J. S. Chen. 2011. Development of an indirect competitive ELISA for simultaneous detection of enrofloxacin and ciprofloxacin. J. Zhejiang Univ. Sci. B 12:884-891. https://doi .org/10.1631/jzus.B1100076.

Zhang, L., Y. Huang, J. Wang, Y. Rong, W. Lai, J. Zhang, and T. Chen. 2015. Hierarchical flowerlike gold nanoparticles labeled immunochromatography test strip for highly sensitive detection of Escherichia coli O157:H7. Langmuir 31:5537-5544. https://doi .org/10.1021/acs.langmuir.5b00592.

Zhao, Y., G. Zhang, Q. Liu, M. Teng, J. Yang, and J. Wang. 2008. Development of a lateral flow colloidal gold immunoassay strip for the rapid detection of enrofloxacin residues. J. Agric. Food Chem. 56:12138-12142. https://doi.org/10.1021/jf802648z.

Zhou, S., L. Xu, H. Kuang, J. Xiao, and C. Xu. 2021. Fluorescent microsphere immunochromatographic sensor for ultrasensitive monitoring deoxynivalenol in agricultural products. Microchem. J. 164:106024. https://doi.org/10.1016/j.microc.2021.106024.

Zhou, S., L. Xu, L. Liu, H. Kuang, and C. Xu. 2020. Development of a monoclonal antibody-based immunochromatographic assay for the detection of carbamazepine and carbamazepine-10, 11-epoxide. J. Chromatogr. B Analyt. Technol. Biomed. Life Sci. 1141:122036. https://doi.org/10.1016/j.jchromb.2020.122036.

\section{ORCIDS}

Chuanlai Xu ๑ https://orcid.org/0000-0002-5639-7102 